\title{
Problems and Countermeasures in the Implementation of the Law of the People's Republic of China on Regional Ethnic Autonomy
}

\author{
Lu Liu \\ Southwest Minzu Research Institute \\ Southwest Minzu University \\ Chengdu, China \\ Jinan Vocational College of Nursing \\ Jinan, China
}

\begin{abstract}
On the basis of sorting out the formulation and development process of The Law of the People's Republic of China on Regional Ethnic Autonomy, this paper discusses that there are still many problems existing in the implementation of the law, including the lack of operability of the highly principled provisions, the difficulty in implementing the principle provisions about the right of autonomy, the lack of supervision mechanism and legal responsibility and the imperfection of the supporting legislation. Besides, the countermeasures and suggestions are put forward respectively.
\end{abstract}

Keywords-law on regional national autonomy; policy of regional national autonomy; problems; countermeasures

\section{INTRODUCTION}

The Formulation and Development Process of The Law of the People's Republic of China on Regional Ethnic Autonomy can be roughly divided into the following stages of development: the initial stage of the establishment of the legal system for regional ethnic autonomy; the stagnation stage of the construction of the Law on Regional Autonomy; the promulgation, implementation and sound development of the Law on Regional Ethnic Autonomy; the continuous improvement of the Law on Regional Ethnic Autonomy and its supporting regulations.

Although the implementation of the Law on Regional Ethnic Autonomy had made certain achievements, there were still many problems. It's a common phenomenon that the interests of the local ethnic minorities were ignored, which made them unable to get the benefits they deserve in the process of the development and utilization of resources and aroused dissatisfaction among the local minority people. Either in the self-construction of the Law on Regional Ethnic Autonomy or in the development of its supporting laws and regulations and the improvement of the local autonomy regulations, there are still imperfections that need to be strengthened and improved. The supporting legislation of the Law on Regional Ethnic Autonomy is weak, and the attention to the right of autonomy of ethnic autonomous areas is insufficient. On the basis of sorting out the problems existing in the implementation of The Law of the People's Republic of China on Regional Ethnic Autonomy, the countermeasures and suggestions are put forward respectively.

\section{THE FORMULATION AND DEVELOPMENT PROCESS OF} THE LAW OF THE PEOPLE'S REPUBLIC OF CHINA ON REGIONAL

\section{ETHNIC AUTONOMY}

The Communist Party of China has attached great importance to solving the problem of ethnic groups since its establishment. After the arduous exploration and practice during the new-democratic revolution period and the guidance of the Marxist ethnic theory, the Communist Party of China eventually established the policy of regional ethnic autonomy as the basic policy to solve the ethnic problems in China, which is a path to solve the ethnic problems in line with China's national conditions. And the Communist Party of China's exploration and experience about the policy of the regional ethnic autonomy before the founding of the People's Republic of China provided an important theoretical and practical basis for the development of The Law of the People's Republic of China on Regional Ethnic Autonomy (Law on Regional Ethnic Autonomy for short). After the establishment of New China, the evolution process of the Law on Regional Ethnic Autonomy can be roughly divided into the following stages of development:

\section{A. 1949 to 1965: the Initial Stage of the Establishment of the Legal System for Regional Ethnic Autonomy}

The Common Program adopted in September 1949 defined the party's policy of regional ethnic autonomy in the form of a fundamental law of the state, clearly determined the regional ethnic autonomy to be a basic national policy, which became the legal basis for the establishment of the legal system for regional ethnic autonomy in the early days after the founding of the People's Republic of China.

On August 8, 1952, the Central People's Government Committee approved the Outline for the Implementation of the Regional Ethnic Autonomy of the People's Republic of China. And in 1954, the first constitution implemented by the People's 
Republic of China made a more comprehensive regulation to the regional ethnic autonomy on the basis of the Common Program.

Due to the emergency and unchecked spread of the "Left" thinking within the Communist Party of China at that time, the good trend of the establishment of the legal system for regional ethnic autonomy was disturbed. And the drafting of the Law on Regional Ethnic Autonomy, which was initiated in 1954, was also put on hold due to the political situation at that time. However, the construction of the legal system for regional ethnic autonomy in this period still developed in twists and turns. From 1955 to 1965 , the autonomous areas formulated a total of 48 separate regulations, of which 45 were organizational regulations for the organs of autonomous governments. [1]

\section{B. 1966 to 1976: the Stagnation Stage of the Construction of the Law on Regional Autonomy}

During the "Cultural Revolution", the Party's national policy was severely damaged. And the drafting of the Law on Regional Ethnic Autonomy was completely stagnant, the provisions of the autonomous areas to formulate autonomous regulations and separate regulations were also abolished, and the legislation of the autonomous areas also stagnated.

\section{1978 to 2001: the Promulgation, Implementation and Sound Development of the Law on Regional Ethnic Autonomy}

After the Third Plenary Session of the Eleventh Central Committee of the Communist Party of China, the drafting of the Law on Regional Ethnic Autonomy was put on the agenda and entered a new period of development with the order of ethnic work brought out from chaos. In 1981, the drafting group of the Law on Regional Ethnic Autonomy was established according to the instructions of the Central Committee of the Communist Party of China and the Standing Committee of the National People's Congress. In 1983, the leading group for the drafting of the Law on Regional Ethnic Autonomy was established with the approval of the Central Committee. After the extensive consultation and the modification of more than ten revisions, the Second Session of the Sixth National People's Congress reviewed and approved the Law on Regional Ethnic Autonomy on May 31, 1984. The implementation of the Law on Regional Ethnic Autonomy marked the further improvement of China's regional ethnic autonomy system and the construction of the legal system of regional ethnic autonomy has embarked on the track of standardization and legalization. In 1991, the State Council issued the Notice on Further Implementing the "The Law of the People's Republic of China on Regional Ethnic Autonomy". On February 28, 2001, the 20th meeting of the Ninth NPC Standing Committee revised and approved the Law on Regional Ethnic Autonomy. The revision of the Law on Regional Ethnic Autonomy was a major measure to uphold and improve the system of regional ethnic autonomy at the beginning of the new century. And it provided the legal guarantee for the continuation of upholding and improving the system of regional ethnic autonomy, and was a milestone in the history of the development of the regional ethnic autonomy system. [2]

\section{2002 to the Present: the Continuous Improvement of the Law on Regional Ethnic Autonomy and Its Supporting Regulations}

With the revision of the Law on Regional Ethnic Autonomy of 2001, the formulation of administrative regulations, specific measures and other supporting laws and regulations to implement the Law on Regional Ethnic Autonomy has become an important task for the construction of China's national legal system. The Decision on Further Strengthening Ethnic Work to Accelerate the Economic and Social Development of Ethnic Minorities and Ethnic Areas by the Central Committee of the Communist Party of China and the State Council [3] issued in May 2005 was not only the first decision on the overall situation of national work made by the Party Central Committee and the State Council since the founding of New China, but also a programmatic document for the guidance of the national work in the new stage of the new century, and it played an important guiding role in the development and perfection of the Law on Regional Ethnic Autonomy.

On May 31, 2005, the State Council issued and implemented the Several Provisions about the Implementation of The Law of the People's Republic of China on Regional Ethnic Autonomy by the State Council. The promulgation and implementation of the regulations was not only another major measure of upholding and improving the system of regional ethnic autonomy and implementing the law of regional ethnic autonomy, but also an important achievement in the construction of China's socialist democracy and legal system. [4] By then, China had initially established a relatively complete system of laws and regulations on the Law on Regional Ethnic Autonomy.

\section{PRoBlems ARISING IN THE IMPLEMENTATION OF THE LAW ON REGIONAL ETHNIC AUTONOMY}

Although the implementation of the Law on Regional Ethnic Autonomy had made certain achievements, there were still many problems which were found in the law enforcement inspection of the Law on Regional Ethnic Autonomy by the Standing Committee of the National People's Congress in July 2006: some departments and localities did not attach importance to the study, propaganda, and education of the Law on Regional Ethnic Autonomy, and their sense of responsibility and consciousness in implementing and enforcing the law were not strong; some of the important provisions of the Law on Regional Ethnic Autonomy were too principled which needed making more specific; relevant supporting regulations were still not improved, of which the supporting regulations of the ministries and commissions of the State Council were not perfect, so the autonomous regulations of the autonomous regions had not been issued, resulting in the fact that the important provisions of the Law on Regional Ethnic Autonomy and the Several Provisions were not satisfactorily implemented.

\section{A. Coordination Between the Interests of Ethnic Autonomous Regions and That of the Central Government}

The coordination between the local interests and national interests is a universal problem exists in the general states. In a unified multi-ethnic country like China, the local interests are 
often intertwined with national interests, which make the issue of interest coordination more complicated. The economic construction in ethnic areas is not only a major event related to the interests of the ethnic minorities, but also an important issue that is in line with the long-term interests of other ethnic groups and that of the national modernization. The improvement of the relations of groups in the country through the development and meeting of groups' interests is a policy and guideline that our country has consistently adhered to. In essence, the national interests and ethnic groups' interests are not contradictory, because the satisfaction of ethnic groups' interests is the realization of greater and indirect national interests. Article 118 of the Chinese Constitution clearly stipulates that the interests of ethnic autonomous areas shall be taken into consideration when the state develops resources and builds enterprises in the ethnic autonomous regions. However, in the process of developing and utilizing the resources in the ethnic regions in the past, it's a common phenomenon that the interests of the local ethnic minorities were ignored, which made them unable to get the benefits they deserve in the process of the development and utilization of resources and aroused dissatisfaction among the local minority people.

\section{B. The Content and System of the Law on Regional Ethnic Autonomy Still Need to Be Improved}

Since the implementation of the Law on Regional Ethnic Autonomy, the Party Central Committee and the State Council have attached great importance to the construction of the system of the national laws and regulations. At present, although China has basically formed a national law and regulation system which is formulated on the basis of the Constitution, taking the Autonomy Law as the core, enacting the autonomous regulations and separate regulations as the main content and endowed with Chinese characteristics. However, either in the self-construction of the Law on Regional Ethnic Autonomy or in the development of its supporting laws and regulations and the improvement of the local autonomy regulations, there are still imperfections that need to be strengthened and improved, which shows that there is still a long distance to the formation of a complete socialist national law system and supervision mechanism.

1) There are two main problems with regard to the contents of the Law on Regional Ethnic Autonomy: First of all, the content of the provisions of the Law on Regional Ethnic Autonomy is relatively principle. And the direct consequence is its poor maneuverability and difficult implementation, and the increase of its maneuverability is the bottleneck for the construction of the Law on Regional Ethnic Autonomy.

Second, the legal language is not standardized and there are too many policy terms, such as "according to the law", "making proper consideration", "autonomous", "as far as possible", and so on. These vague statements with strong policy characteristics not only go against to the observation, enforcement and judgment of the Law on Regional Ethnic Autonomy, but also seriously affect the authority of it.

2) From the perspective of the system structure of the Law on Regional Ethnic Autonomy: The most prominent problem is the lack of "legal responsibility" provisions, that is, there is no "rules related to penalty". And the lack of "legal responsibility" make against the observance and implementation of the Autonomy Law, and conduction of effective supervision and judicial activities as well.

\section{THE WEAK SUPPORTING LEGISLATION OF THE LAW ON REGIONAL ETHNIC AUTONOMY}

\section{A. Formulation of the Separate Laws}

The lack of separate laws directly affects the relevant legal guarantees in the social field of ethnic regions, which leads to the lack of legal basis for relevant issues in the social field in the process of legal construction of social management. As for the current legalization of Chinese society, the separate laws and regulations that are urgently needed to be formulated include the Law on the Promotion of Economic Development of Ethnic Autonomous Areas, the Law on the Promotion of Ethnic Minorities Education, and the Law on the Protection of Ethnic Minorities Culture.

\section{B. Formulation and Improvement of the Autonomous Regulations and Separate Regulations}

The Article 19 of Law on Regional Ethnic Autonomy stipulates that the people's congresses in the ethnic autonomous areas have the right to formulate autonomous regulations and separate regulations in accordance with the local political, economic and cultural characteristics. At present, the autonomous regulations and separate regulations that have been issued in some ethnic autonomous regions in China still have the following imperfections: the contents are outdated and monotonous, the specific content lacks ethnic features and regional characteristics, the amendments to the autonomous regulations and separate regulations of the ethnic autonomous areas are not timely, and the legislative procedures or amendment processes need to be improved. [5] And the ethnic minority regions shall timely establish, abolish and amend the autonomous regulations and separate regulations on the basis of the reference to the provisions of the Law on Regional Ethnic Autonomy and the consideration of the actual conditions of their respective ethnic regions.

\section{Effective Exercise of the Right of Alteration}

At present, there are many problems that need to be solved in the implementation of the right of modification. For example, the non-uniformity of the subject of the modification right will lead to the phenomenon of preemptive profits and profitless prevarication. In addition, among the various laws and regulations enacted in China, only a few laws and regulations can be found clearly stipulate that the ethnic autonomous areas have the right to make modifications or supplements, while in most other laws and regulations, the provisions on the possibility of the alteration or supplementary enforcement in national autonomous areas have not been proposed. And it has seriously affected the exercise of the right of modification in the ethnic autonomous areas, which may also be the main factor resulting in the imperfect construction of legalization of the social management in these regions. 


\section{Insufficient Attention to the Right of Autonomy of Ethnic} Autonomous Areas

The right of autonomy is the core and key to the implementation of regional ethnic autonomy. Without the autonomy right, the practice of the ethnic regional autonomy will exist in name only. The establishment and exercise of the autonomy right cannot be separated from the respect, protection and support of the higher-level state organs and this is the important guarantee for the self-governing organs to exercise their autonomy rights effectively. And the central state organs do not give enough respect for the autonomy rights of the ethnic autonomous areas; in other words, they have made too many restrictions and limits on it and just delegate less power to the autonomous areas to exercise the right. Some of the policies and measures formulated by the higher authorities are very rigid, or even transparently imply the violation of the Law on Regional Ethnic Autonomy are also enforced, resulting in insufficient guarantee of the autonomy right of the ethnic areas.

In the operation and guarantee of the practice of dual functions and powers by organs of self-government, some administrative organs in the ethnic autonomous areas and many national administrative organs of higher levels all paid different degrees of attention on the emphasis of the functions and powers of the local state organs and the belittlement of the autonomy right of the organs of self-government. The root of the understanding of this kind of problem lies in the weak selfgoverning consciousness of the staff in some departments of the self-governing organs, the weak consciousness of the staff in some departments of the higher-level state organs to guarantee the self-governing organs' exercises of autonomy rights, and the staff of the above-mentioned two parties have insufficient understanding of the status of the autonomy right in the organs of self-government.

\section{COUNTERMEASURES AND SUGGESTIONS FOR THE FURTHER IMPLEMENTATION OF THE LAW ON REGIONAL ETHNIC AUTONOMY}

\section{E. Strengthening and Improving the Law on Regional Ethnic Autonomy and the Construction of Its Supporting Laws and Regulations}

1) It is proposed to add provisions on "legal liability": As a basic law implemented in the ethnic areas of China, the Law on Regional Ethnic Autonomy should also contain clear provisions on "legal liability" like other laws and regulations. The lack of the "legal responsibility" clause in the currentLaw on Regional Ethnic Autonomy is likely to result in the failure to investigate the illegal acts of the state organs, which directly affects the implementation of the Law on Regional Ethnic Autonomy. Therefore, it is necessary to add special "legal responsibility" chapters such as civil, criminal, administrative and political responsibilities.

2) In view of the problems existing in the current construction of the supporting laws and regulations, great efforts will be made on the following aspects: First, the relevant departments of the State Council should formulate the regulations of the implementation of the Law on Regional
Ethnic Autonomy as soon as possible. Second, the autonomous regions and provinces and the municipalities directly under the Central Government with autonomous areas should formulate the laws and regulations of the implementation of the Law on Regional Ethnic Autonomy as soon as possible. Third, the act on autonomous regional autonomy should be issued as soon as possible. The implementation of the autonomous region's autonomous regulations is the most necessary breakthrough in the building of China's national legal system. So far, none of the autonomous regulations of China's five autonomous regions have been approved, which is extremely incompatible with the practice of the vigorous development of the national legal system in China. Therefore, the difficulty in the promulgation of autonomy regulations in autonomous regions is a major issue that needs to be urgently resolved in the construction of the national legal system in China.

\section{F. Effectively Protect the Right of Autonomy in Ethnic Autonomous Regions}

Although the Constitution and the Law on Regional Ethnic Autonomy have endowed a wide range of autonomy rights to the organs of self-government, these provisions are too principled to be operated. Further strengthening and guaranteeing the exercise of autonomy rights of the organs of self-government is an important part that needs to be improved in the current construction of the Law on Regional Ethnic Autonomy, and achievements should be made especially in the respects of fiscal transfer payments, matching fund reduction, ecological environmental protection compensation and resource development compensation.

\section{G. Improve the Higher-level States' Duties to Lead and Help the Ethnic Autonomous Areas}

The Law on Regional Ethnic Autonomy, amended in 2001, further promoted the leadership and assistance of the higherlevel state organs to be their statutory duties. The name of this chapter was changed to: "The duties of the higher-level state organs" with the largest number of additional and corrective provisions. And its content includes the practice of the principle of leadership, assistance and guidance in line with the actual situation suitable for ethnic autonomous areas, the attraction of domestic and foreign funds, the arrangement of national investment projects, the special policies to support the national autonomous areas in the areas of finance, education, science and technology, culture and talents, and the legal provision that formed on the basis of the existence of the counterpart support between the economically developed areas and the ethnic autonomous areas in recent years. And there are many further implementation work needs to be done in the implementation process, such as regulating the preferential policies for guiding and encouraging the domestic and foreign funds to invest in the ethnic autonomous areas, increasing the financial support for the ethnic autonomous areas, expanding the fiscal transfer payments to ethnic autonomous areas, further realizing the compensation of output natural resources and ecological environmental benefits, and enhancing the maneuverability of the above mentioned provisions. 


\section{H. Strengthening the Implementation and Supervision of the Law on Regional Ethnic Autonomy}

The imperfection of the supervision mechanism and the lack of supervision are one of the bottlenecks in the construction of the Law on Regional Ethnic Autonomy. In general, the law enforcement supervision mechanism of China' national laws and regulations is far from being formed, and the legal supervision is in a weak state.

First of all, the supervision awareness of the National People's Congress must be strengthened. The basic duties of the people's congresses at all levels and their standing committees in the ethnic areas include listening to the People's Government's guidelines about the implementation of the Law on Regional Ethnic Autonomy at any time or on a regular basis, listening to the People's Government's special reports on the national policy in ethnic minority areas, the increase of the intensity of the administrative law enforcement, and the appointment of the relevant leaders to conduct large-scale law enforcement inspections in the ethnic areas. And people's congresses at all levels in the ethnic areas should make full use of their work functions and exercise their powers of inquiry and application for explanation about the implementation of the Law on Regional Ethnic Autonomy. In the field of administrative law enforcement, the National People's Congress should always supervise whether the government is contrary to law and make it public.

Second, the supervision of the judicial organs should be increased. The supervision of the judicial organs is of great value for protecting the legitimate rights and interests of the citizens, legal persons and social organizations in the ethnic autonomous regions and guaranteeing the fair law enforcement. Specifically, as for the administrative cases in violation of the Law on Regional Ethnic Autonomy due to the violations of the legal rights of ethnic minority citizens and the violations of the right to self-government of national autonomous areas, the People's Procuratorate shall, in accordance with the law, carry out investigation, arrest and prosecution to the cases of duty crimes committed by administrative law enforcement agencies and administrative law enforcement personnel. And the people's courts shall promptly and fairly handle the cases according to the facts and laws.

Third, the supervision of the news and public opinions should be strengthened. The improvement of the supervision of the public opinions in the ethnic autonomous areas should be carried out from the following two respects, on the one hand, it is necessary to develop a group of minority journalists in the ethnic areas, and their important task is to better reflect the existence of the illegal phenomenon in the law enforcement work by the administrative organs and judicial organs in the ethnic autonomous areas, which can not only promotes the progress of journalists of other ethnic minorities and gradually improves the quality of the subject of public opinion supervision, but also advances the effective implementation of the Law on Regional Ethnic Autonomy. On the other hand, the Regulations on Public Opinion Supervision should be formulated in accordance with the actual situations in the ethnic areas, so as to make corresponding provisions on the rights and obligations of the citizens in the ethnic areas, the protection and relief of journalists and the legal responsibilities.

\section{CONCLUSION}

In view of the problems existing in the implementation of The Law on Regional Ethnic Autonomy, the countermeasures and suggestions for the further implementation of the Law are put forward, including strengthening the Law and the construction of its supporting laws and regulations, effectively protect the right of autonomy in ethnic autonomous regions, improving the higher-level states' duties to lead and help the ethnic autonomous areas, and strengthening the implementation and supervision of the Law. Through these countermeasures, we believe the Law will be more perfect and make greater contributions to China's national unity and political stability.

\section{REFERENCES}

[1] Department of Political and Legal Affairs of the State Ethnic Affairs Commission of the People's Republic of China, "General Code for Chinese Regional National Autonomy Laws and Regulations," Minzu University of China Press. Beijing, 2002.

[2] Ao Junde, "New Achievements in the Construction of China's National Legal System at the Beginning of the New Century-On the Revision of the Law on Regional National Autonomy," Ethnic Studies, 2001(4).

[3] "Research and Deployment to Further Strengthen Ethnic Work and Accelerate the Development of Ethnic Minorities and Ethnic Areas," The People's Daily, 2005-06-01(1).

[4] Jin Bingyan. Dong Qiang, "The 60th Anniversary of the New China's Regional National Autonomy Policy - The Third Series of National Policies to Commemorate the 60th Anniversary of the Founding of New China," Heilongjiang National Series, 2009 (5).

[5] Li Hanwei, "On the Dilemma and Solution of the Formulation and Improvement of the Autonomy Regulations," Journal of Northwest Minzu University, No. 2, 2008. 